\section{Eggs of Lestinogomphus africanus (Fraser)}

IN June $1955 \mathrm{I}$ had the good fortune to obtain batches of eggs from two females of the archaic dragonfly Lestinogomphus africanus (Fraser) taken near Kuru, Northern Nigeria. These eggs presented a feature which has apparently not hitherto been described in the Odonata, although similar structures are known in certain genera of the Ephemeroptera. The posterior pole of the egg was produced into a coiled filament about $30 \mathrm{~mm}$. in length, at first tightly wound and forming a small cap over the end of the egg, but opening out into a loose spiral on contact with the water.

A fuller description of the egg and of the early nymphal stages will shortly be published elsewhere by myself and Mr. A. E. Gardner, who has reared some of these eggs up to the third instar, so no further details are necessary here.

Morgan $^{1}$ described and figured very similar structures in the egg of the mayfly Stenonema, and these have been discussed by Needham, Traver and $\mathrm{Hsu}^{2}$. They are generally considered to be an adaptation to life in rapidly flowing water and to serve for anchorage, although eggs both with and without special anchoring structures can be laid in both rapid streams and quiet ponds.

Dr. P. S. Corbet, of Jinja, Uganda, informs me that he has very recently obtained some eggs from Ictinogomphus ferox (Rambur) and finds that they have filaments similar to those shown in some sketches of Lestinogomphus eggs that I had sent him; it therefore appears possible that these filaments may be found in a number of different genera of the Gomphidae. Dr. Corbet has found fully grown nymphs of both Lestinogomphus and Ictinogomphus in sheltered muddy portions of lakes in Uganda, and considers that the presence of these filaments may be evidence of rheophilic ancestry in species at present able to live in a stagnant and muddy environment. In Nigeria, Ictinogomphus breeds in muddy ponds; but the Lestinogomphus in question were taken beside a flowing stream, so it would appear that the latter species is able to breed in both running and stagnant water.

I am grateful to Dr. Corbet for permission to quote his observations.

\section{R. Moylan Gambies}

Veterinary Research Laboratory,
Vom, Nigeria. Dec. 3.

${ }^{1}$ Morgan, A. H., Ann. Ent. Soc. Amer, 6, 371 (1931).

${ }^{2}$ Needham, J. G., Traver, J. R., and Hsu, Y.-C., "The Biology of Mayflies" (Ithaca, New York, 1935).

\section{Ink Ejection by Cephalopoda}

IT has long been said that the ink discharged by the great majority of cephalopods is ejected as a black cloud, under cover of which the animal may escape from a threatened attack. That this is false is apparent to anyone who has watched the phenomenon. The ink (of such cephalopods that I have seen) initially does not form a cloud, but remains a discrete, dark, viscous mass; water turbulence breaks up the mass, dispersing it in the form of streaks indicating the direction of the current flow, and even in a small volume of water such as an aquarium tank, eloud formation takes place only after some considerable time. The importance of this may not be readily apparent in a brightly illuminated aquarium; but the following observation, made under conditions of reduced light intensity one evening aboard the Singapore Regional Fisheries Research Vessel Manihine (October 1955), appears to present the true interpretation of this escape reaction.

I attempted to catch a small (unidentified) squid, some three inches long, which was being kept alive in a large, light-coloured wooden tub. The squid displayed evidence of agitation as it was manœuvred into a suitable position for capture, changing colour rapidly in the manner which is well known. When my hand was within about nine inches of the animal the squid assumed a dark coloration and appeared to become stationary. I seized the dark object, but it proved to be nothing more than a volume of ink ; the squid was found to be at the opposite side of the tub. On repeating the attempted capture, I was able to see that, after assuming the dark coloration, the squid discharged a quantity of ink sufficient to produce a discoloured volume of water of similar size to the squid itself, simultaneously becoming pale in colour and moving away rapidly around the perimeter of the tub. Although I had been anticipating a discharge of ink during the first attempted capture, so efficiently had the operation been performed, and so intent had I been on the capture of a dark-coloured creature, that I had failed completely to see the escape of the squid in its light-coloured guise. I had the advantage of viewing the events laterally: a 'natural' enemy would have suffered the additional complication of having the ink discharged between it and the squid.

I have not yet had the opportunity of comparing with this the behaviour of other cephalopods, but in the case of the specimen examined the important features of the escape reaction are : (1) the assumption of a dark coloration immediately before (2) the discharge of a quantity of ink sufficient only to discolour a volume of water of similar size to the animal itself, this ink functioning primarily as a decoy, but also masking to some extent (3) the rapid change of the animal to a lighter colour and (4) the rapid departure of the animal from the scene of the impending attack.

$$
\text { D. N. F. HALL }
$$

Singapore Regional Fisheries Research Station, 4 Nicoll Drive, Changi, Singapore 17. Nov. 25.

\section{Variation in Mortality with Differences in Humidity among Mosquitoes exposed to BHC, Dieldrin and DDT}

SINCE 1949 a long series of trials of residual insecticides has been carried out by this Unit at Taveta, Kenya, using the trap-hut method originated by Thompson ${ }^{1}$. In a number of the trials carried out since 1952, using $\mathrm{BHC}$ and dieldrin, a pronounced seasonal effect has been observed. During the dry season, the percentage mortality among female anophelines entering the houses has frequently declined, increasing comparatively rapidly at the onset of the next rainy season. This has been noted in huts lined with an impervious surface (banana leaf) treated with dieldrin and in others with reed roofs 